\title{
Splenectomy May Decrease the Risk of Hepatocellular Carcinoma in Patients with Liver Cirrhosis: A Multi-institutional Cohort Study
}

\section{Xu-Feng Zhang}

Xi'an Jiaotong University https://orcid.org/0000-0002-4483-7326

Yang Liu

Xi'an Jiaotong University

Jian-Hui Li

Xi'an Jiaotong University

Peng Lei

Ningxia Medical University

Xing-Yuan Zhang

Binzhou Medical University

\section{Zhen Wan}

Medical College of Nanchang University

\section{Ting Lei}

Shaanxi University of Chinese Medicine

\section{Xiao-Ning Wu}

Xi'an Jiaotong University

Hong-Fan Ding

Xi'an Jiaotong University

Zhi-Da Long

Xi'an Jiaotong University School of Medicine

\section{Zong-Fang Li}

Xi'an Jiaotong University

\section{Rongqian Wu}

Xi'an Jiaotong University School of Science

\section{Xi Chen}

Xi'an Jiaotong University

\section{Jian-Xiong Wang}

Xi'an Jiaotong University

\section{Peng Yuan}

Ningxia Medical University

\section{Yong Li}


Medical College of Nanchang University

Jun Zhou

Shaanxi University of Chinese Medicine

Timothy M. Pawlik

Ohio State University College of Medicine

Yi Lyu (D luyi169@126.com)

the First Affiliated Hospital of Xi'an Jiaotong University

\section{Research article}

Keywords: Splenectomy, liver cirrhosis, hepatocellular carcinoma, portal hypertension, hypersplenism

Posted Date: August 26th, 2020

DOl: https://doi.org/10.21203/rs.3.rs-53468/v1

License: (c) (i) This work is licensed under a Creative Commons Attribution 4.0 International License. Read Full License 


\section{Abstract}

\section{Background}

Hypersplenism is a common consequence of liver cirrhosis and a risk factor of hepatocellular carcinoma (HCC) development. The objective of the current study was to identify whether splenectomy for treatment of hypersplenism has any impact on risk of HCC.

\section{Methods}

Patients who underwent splenectomy for hypersplenism secondary to liver cirrhosis and portal hypertension between 2008 and 2012 were included from seven University Hospitals in China, whereas patients receiving medication treatments for liver cirrhosis and portal hypertension (non-splenectomy) at this time period were also included as control.

Results

A total of 871 patients with liver cirrhosis and hypertension were included synchronously from 7 tertiary hospitals. Among them, 407 patients had a history of splenectomy for hypersplenism, whereas 464 patients who received medical treatment but not splenectomy (non-splenectomy group). The cumulative incidence of HCC development at 1,3, 5 and 7 years were $1 \%, 6 \%, 11 \%$ and $16 \%$ in splenectomy group, and $2 \%, 10 \%, 17 \%$ and $24 \%$ in non-splenectomy group in the unadjusted cohort (Breslow test $=7.7$, $p=0.005)$. Consistently, in the matched cohort, the cumulative rates of HCC diagnosis at 1, 3, 5 and 7 years were $1 \%, 6 \%, 7 \%$ and $15 \%$ in splenectomy group, and $1 \%, 6 \%, 15 \%$ and $23 \%$ in non-splenectomy group (Breslow test $=4.9, p=0.028$ ). On multivariable analysis, splenectomy was independently associated with decreased risk of HCC development (HR 0.55, 95\% Cl, 0.32-0.95, $p=0.031$ ).

Conclusion

Splenectomy for treatment of hypersplenism may decrease the risk of HCC development.

\section{Background}

Hepatocellular carcinoma (HCC) is a well-known consequence of liver cirrhosis being the second most common cause of cancer-related death around the world.[1-3] Liver cirrhosis, secondary to hepatitis B virus (HBV), hepatitis $\mathrm{C}$ virus (HCV) infection, or alcohol consumption, is present in more than $80 \%$ of patients with HCC. Although portal hypertension, and subsequent hypersplenism and esophagogastric variceal hemorrhage are the most important causes of death, HCC development as a result of liver cirrhosis is also a major reason for poor outcomes among patients with liver cirrhosis.[4]

Transjugular intrahepatic portosystemic shunt (TIPS) is one of the modalities for treatment of portal hypertension and associated complications, such as refractory ascites and hypersplenism. TIPS can effectively reduce portal pressure by creating a canal with stent between the portal vein and a hepatic 
vein or the cava vein. Although TIPS is not a surgical shunt, it generates circulatory, hemodynamic, and functional changes, and significantly influences hepatocyte proliferation and portal blood flow. [5-9] Several studies have demonstrated that TIPS might increase the risk of HCC development among patients with liver cirrhosis,[5, 6] whereas other studies have failed to note this association.[7-9]

Hypersplenism is characterized by anemia, leucopenia, thrombocytopenia and splenomegaly. Hypersplenism aggravates intrahepatic inflammatory injury via liver-spleen crosstalk.[10, 11] For example, immunological functions of patients with hypersplenism might be impaired, such as an increased CD4/CD8 ratio and impaired function of macrophages, which may promote hepatocarcinogenesis. $[10,12]$ Increased expression of TGF- $\beta 1$ and decreased expression of cytokines such as IL- 6 in the spleen among patients with liver cirrhosis might promote progression of liver cirrhosis. [11] In fact, high splenic volume has been independently associated with post-hepatectomy HCC recurrence and overall survival.[13] Of note, recent studies have demonstrated that hypersplenism secondary to liver cirrhosis and portal hypertension was an independent risk factor associated with HCC development.[14-16] The association between hypersplenism and HCC development might be multifactorial but also partially as a result of thrombocytopenia, since thrombocytopenia has also associated with an increased risk for HCC development.[17] Taken together, hypersplenism may cause sustained liver injury and immune suppression, and thus be a risk factor for HCC development.

Splenectomy is a potential treatment of hypersplenism secondary to liver cirrhosis and portal hypertension. Whether splenectomy for treatment of hypersplenism has any impact on HCC development among patients with liver cirrhosis and portal hypertension remains unknown. As such, the objective of the current study was to evaluate the possible impact of splenectomy on risk of HCC development among patients with liver cirrhosis using a multi-institutional database.

\section{Methods}

\section{Study cohort}

A retrospective study was performed based on a database from seven high-volume University hospitals. Patients undergoing splenectomy between January 2008 to December 2012 for the treatment of hypersplenism secondary to HBV or HCV related liver cirrhosis and portal hypertension were included. Overall, 13 patients died within six months after surgery and were excluded from the study. In addition, 9 patients who underwent liver transplantation after splenectomy for end-staged liver disease before developing HCC were also excluded, since liver transplant eliminated the risk factor of the cirrhotic liver to cause HCC. Following exclusion of these patients, 407 patients remained in the analytic cohort.

For the control group, all patients with HBV or HCV-related liver cirrhosis admitted to any one of the 7 institutions and treated conservatively during the same time period were randomly selected in 2:1 fashion compared with the splenectomy group. Patients who died or developed HCC within six months after the first admission were excluded as the detection of HCC within six months might have due to a missed diagnosis / occult HCC at the time of first admission. Patients undergoing liver transplant or TIPS for 
non-HCC indication during follow up were also excluded. Treatment with TIPS may have some influence on the development of HCC.[5] While patients undergoing liver transplant before development of HCC were excluded, patients receiving a liver transplant for HCC were included.

Patients were matched so that the non-splenectomy group was comparable to splenectomy group. Matching selection criteria included: Child-Pugh class A or B of liver function with one of the three following conditions: reduced counts of white blood cells $\left(<3 \times 10^{9} / \mathrm{L}\right)$, low level of hemoglobin $(<110 \mathrm{~g} / \mathrm{L})$ or decreased level of platelets $\left(<100 \times 10^{9} / \mathrm{L}\right)$. In total, 464 patients were included who were managed conservatively. The research was approved by the Ethics Committees of each participating centers. A waiver of informed consent was obtained, since the data were analyzed from the electronic medical record and reported without personal identifiers.

HBV infection was defined as positive in the presence of serum hepatitis B surface antigen ( $\mathrm{HBsAg})$ or anti-hepatitis B core antibodies (HBcAb). HCV infection was defined as positive for serum hepatitis $\mathrm{C}$ antibody. All clinical and biochemical data were documented at the first admission or within 48 hours prior to surgery. Child-Pugh score was calculated for each patient based on the recorded data. Diagnosis of hypersplenism was made when the patient presented with splenomegaly, anemia, leucopenia, and thrombocytopenia. MELD was calculated according to the following equation: $9.57 \times$ [ Ln creatinine $(\mathrm{mg} / \mathrm{dL})]+3.78 \times[\mathrm{Ln}$ bilirubin $(\mathrm{mg} / \mathrm{dL})]+11.2 \times \mathrm{Ln}$ INR $]+0.643 .[18]$

\section{Treatments and follow-up}

Splenectomy was performed openly or laparoscopically with or without pericardial devascularization. The indication for splenectomy was hypersplenism with anemia, leucopenia and/or thrombocytopenia. For the non-splenectomy group, all patients were treated conservatively for complications of liver cirrhosis and portal hypertension without TIPS, splenectomy or liver transplant before HCC development during follow up. Anti-HBV or -HCV medications were prescribed by the hepatologists. Medications for chronic hepatitis B were interferon-a (IFNa) and nucleostide analogues, including lamivudine, entecavir, tenofovir disoproxil fumarate, adefovir dipivoxil, and telbivudine. Treatment of HCV included combination of IFNa, sofosbuvir and/or ribavirin. All patients were followed from the day of splenectomy or the first admission (non-splenectomy group) until death or the end of the study (September 2017).

\section{Diagnosis of HCC}

During follow up, patients from the two groups were followed with the same protocol of HCC surveillance. Abdominal ultrasonography, examination of liver function and a-fetoprotein were routinely performed every three to six months. Diagnosis of HCC was mainly based on pathological examination via hepatectomy or biopsy. However, if the histological examination was non-diagnostic, then the diagnosis was made based on the increased a-fetoprotein (AFP) levels $>20 \mu \mathrm{g} / \mathrm{L}$ and characteristic features of imaging examination. After diagnosis of HCC, patients were referred to the liver surgeons or hepatologists for further treatments. 


\section{Propensity score matching analysis}

To reduce selection bias, PSM analysis was utilized to balance the general characteristic, hepatitis and treatments, Child-Pugh classification, and MELD scores of the patients between splenectomy and nonsplenectomy groups. Propensity score analysis with 1:1 matching was performed to generate matched pairs of the patients. Binary logistic regression with the selected variables was used to generate a continuous propensity score from 0 to 1 . A one-to-one nearest-neighbor matching without replacement between patients receiving splenectomy and conservative treatments was used to select patients into subsequent analysis. [19]

\section{Statistical analysis}

Data were expressed as mean \pm standard deviation (S.D.) for quantitative variables or number (percentages) for qualitative variables. Student $t$ tests or Mann-Whitney $\mathrm{U}$ test were used to compare quantitative variables between the two groups. Chi-Square test or Fisher's exact test was carried out to compare qualitative variables among the groups. The cumulative incidence of HCC was calculated by Kaplan-Meier analysis and the curves were plotted and compared using Breslow test. The overall survival was calculated by the Kaplan-Meier method, and the differences in survival between the groups were compared using the log-rank test. To evaluate HCC risk and protective factor, all the potential factors with a $p$ value $<0.10$ in univariate analysis by Breslow test were enrolled into a Cox proportional hazard regression model for multivariate analysis. $\mathrm{HR}$ and $95 \% \mathrm{Cl}$ were calculated for splenectomy versus nonsplenectomy group, and other factors correlating with HCC risk. Statistical analysis was carried out using SPSS 22.0 (SPSS Inc., Chicago, IL). $p<0.05$ was considered statistically significant.

\section{Results}

\section{Comparison of the study groups at baseline}

Baseline clinicopathological characteristics in the splenectomy and non-splenectomy groups were compared (Table 1). Patients in the splenectomy group were younger and more often female versus patients in non-splenectomy group ( $p=0.048$ and 0.006 , respectively). Patients undergoing splenectomy had better underlying liver function measured by Child-Pugh scores and the Model for End-stage Liver Disease (MELD) scores compared with non-splenectomy group (all $p<0.05$, Table 1). Although etiology of liver cirrhosis was similar between the two groups, high viral load (HBV DNA > $1000 \mathrm{copy} / \mathrm{ml}$ ) and antiviral treatments were more frequent in non-splenectomy versus splenectomy group (both $p<0.05$ ). Compared with patients who did not undergo a splenectomy, patients who had a splenectomy were likely to have severe pancytopenia, lower serum level of alanine aminotransferase (ALT), aspartate aminotransferase (AST) and total bilirubin, but increased albumin (all $p<0.01$, Table 1). Of note pancytopenia resolved after splenectomy. Renal and coagulation function were no different between the two groups. Moreover, $53.6 \%$ 
$(218 / 407)$ of patients in the splenectomy group had severe esophagogastric varices. In the surgery group, $88 \%(358 / 407)$ of patients underwent splenectomy and pericardial devascularization.

\section{Development of HCC}

Median follow-up time was similar in the surgery and control groups (63 [range, 8-103] and 62 [range, 12104] months, respectively). The cumulative incidence of HCC development was much lower among patients who had a splenectomy versus individuals who did not (Hazard ratio [HR] 0.63, 95\% confidence interval [CI] 0.44-0.90, $p=0.005$, Breslow=7.7) (Figure 1A). The cumulative HCC incidence at 1-, 3-, 5- and 7years were $1 \%, 6 \%, 11 \%$ and $16 \%$ among patients undergoing splenectomy, and $2 \%, 10 \%, 17 \%$ and $24 \%$ among patients receiving medication treatment only, respectively.

\section{Splenectomy and Risk of HCC}

Overall survival of the patients in the two groups was comparable (splenectomy: 1-, 3-, 5- and 7-year survival $100 \%, 97 \%, 91 \%$ and $86 \%$ vs. no splenectomy: $100 \%, 97 \%, 92 \%$ and $84 \%$; $p=0.899$ )(Figure $2 A$ ). However, on cox proportional hazard regression modeling was several demographic, virus and liverrelated factors were associated with development of HCC. Specifically, on univariate analysis, age, male gender, smoking, HBV DNA > 1000 copy/ml were each associated with an increased risk of HCC, whereas splenectomy and anti-HBV treatment were associated with a lower incidence of HCC (all $p<0.1$, Table 3). On multivariate analysis, age and male gender remained associated with a higher incidence of HCC development, while patients with a history of splenectomy had a lower incidence of $\mathrm{HCC}(\mathrm{HR} 0.55,95 \% \mathrm{Cl}$ 0.32-0.95, $p=0.031$ ) (Table 3).

Propensity score matching (PSM) analysis utilizing variables such as age, gender, liver function, HBV and HCV titers, anti-HBV and anti-HCV treatments, diabetes, smoking and alcohol use was then performed. Specifically, 233 pairs of patients were generated in a matched cohort (Table 2). PSM confirmed that patients who underwent splenectomy had a lower incidence of HCC versus patients who did not undergo splenectomy (HR 0.53, 95\% Cl 0.31-0.91, $p=0.028$, Breslow=4.9) (Figure 1B). In fact, after PSM, the cumulative incidence of HCC at 1-, 3-, 5- and 7-years was $1 \%, 6 \%, 7 \%$ and $15 \%$ among patients who had a splenectomy versus $1 \%, 6 \%, 15 \%$ and $23 \%$, respectively, among patients who did not undergo nonsplenectomy.

\section{Clinical outcomes of HCC patients}

In total, 49 patients $(12.0 \%)$ in the splenectomy group and 75 patients $(16.2 \%)$ in the non-splenectomy group developed HCC during follow-up. While liver function and tumor status were comparable between the two groups, patients with HCC who had a previous splenectomy were less likely to undergo resection versus HCC patients in non-splenectomy group $(12.2 \%$ vs. $33.3 \%, p=0.008)$ (Table 4$)$. The utilization of the tumor-directed treatments (e.g. surgical resection, liver transplant, TACE and radiofrequency ablation) was similar among patients who had previously did or did not undergo a splenectomy $(59.2 \%$ vs. $69.3 \%$, 
respectively; $p=0.246)$. In turn, overall survival of patients with HCC was not different in the splenectomy versus non-splenectomy groups ( $p=0.493$, Figure $2 B$ ).

\section{Discussion}

The spleen is the largest lymphatic organ in the human body and is vital to antibacterial, antifungal and antitumor immune activity.[20] Hypersplenism secondary to liver cirrhosis and portal hypertension has been identified as a strong risk factor for HCC development.[14, 15, 21] In fact, splenectomy for hypersplenism among patients and tumor-bearing animals has been associated with improved liver function, enhanced anti-viral effects, and improved anti-tumor immune function [12, 22-27]. However, whether splenectomy for treatment of hypersplenism has any impact on HCC development among patients with liver cirrhosis and portal hypertension has not been previously investigated. The current study was important as it was the first study to define a possible decreased risk of HCC development among patients undergoing splenectomy. Specifically, patients who had a previous splenectomy had a $37 \%$ decreased risk of HCC in the unadjusted cohort and a $47 \%$ decrease risk in adjusted cohort compared with non-splenectomy patients.

Splenectomy was an independent factor associated with decreased HCC development among patients with liver cirrhosis on multivariate analysis. A previous single-center study had noted that splenectomy was less frequently performed among cirrhotic patients who developed HCC versus patients who did not develop HCC.[16] Consistent with the present study, older age, male gender and smoking as host factors have been well documented as risk factors promoting HCC development in patients with liver cirrhosis. [28-30] Of note, differences in the HCC incidence among the splenectomy versus non-splenectomy groups were only notable 5 years after the initial treatments. These findings implied that the protective effect of splenectomy on hepatocarcinogenesis was manifested after a prolonged period of time due to decreased portal vein pressure, relieved hepatocytes and sinusoidal endothelial cells injury, progressive liver regeneration and repair, and recovered immune function.[20,30-32] While HCC incidence was lower among patients who underwent splenectomy, overall survival was no different among patients who did versus did not have a splenectomy $(p=0.899)$. The for lack in difference in overall survival may be partially explained by the low incidence of HCC in both groups, and early treatment due to strict surveillance in China.

The role of the spleen in development and progression of liver cirrhosis and HCC has been increasingly recognized. A number of studies have demonstrated that splenectomy in cirrhotic patients improved liver function, although the mechanism remains obscure. In addition to TGF- $\beta 1$, a recent study from our own group identified differential expression of 136 splenic-derived cytokines among cirrhotic patients versus healthy subjects; splenectomy led to significant changes of 28 cytokines, which were mainly involved in progression of liver cirrhosis and development of HCC.[33] Moreover, splenectomy for hypersplenism promotes platelet count and expression of platelet-derived serotonin, as well as peripheral and hepatic macrophages/monocytes, which attenuate liver fibrosis and promote liver regeneration by upregulating 
HGF and Wnt signaling.[23, 34] Collectively, these data provide biological, mechanistic plausibility to the clinic findings reported in the current study.

While hypersplenism was associated with HCC recurrence and poor outcome, splenectomy for hypersplenism improved outcomes among patients undergoing curative resection for HCC.[13, 16] Similarly, using a murine orthotopic model, Li and colleagues had demonstrated that splenectomy prevented tumor growth and improved immune responses of tumor-bearing hosts by decreasing myeloidderived suppressor cells, and increasing natural killer (NK) cells and NK T cells in liver tumor tissues.[26] Similarly, Liu et al. demonstrated in a murine model that splenectomy accelerated liver regeneration after partial hepatectomy of HCC by improvement of the tight junction formation which helped in establishment of hepatocyte polarity via Par 3-aPKC.[35] In turn, splenectomy for hypersplenism among cirrhotic patients may decrease the risk of HCC development in three ways: (1) improvement in liver function via increase in the platelet count, accumulation of macrophages/monocytes, as well as resolution of portal hypertension and alleviation of fibrosis[23, 31, 33] (2) promotion of liver regeneration via removal of hepatic regeneration inhibition factors in the spleen (TGF- $\beta$, TNF-a, etc.) and enhancement of hepatic regeneration promotion factors (Hepatocyte growth factor and receptor, heat shock protein, heme oxygenase-1, Wnt signaling, etc.) $[23,33,34]$ (3) better anti-tumor immune functions among patients due to recovery of T lymphocyte subsets and Th1/Th2 cytokines, such as increase of CD4, interferon- - , IL-2, and decrease of CD8 and IL-10.[12, 24, 26](Figure 3)

Several limitations should be considered when interpreting results in the current study. The retrospective nature of the present study may have introduced selection bias given that splenectomy was mostly confined to patients with severe pancytopenia. PSM analysis was utilized, however, to mitigate potential selection bias and confounding by matching patients relative to known baseline characteristics in the splenectomy and non-splenectomy groups. Of note, in the matched cohort, baseline characteristics, liver function, hepatitis titers and anti-viral treatments between the two groups were comparable. The control group may, however, not have fully reflected the nature disease progression of patients with HBV- or HCVrelated liver cirrhosis. As such, we randomly selected patients in the non-splenectomy group as controls, which was a previously utilized approach.[5, 7, 36] Of note, the incidence of HCC in non-splenectomy group was approximately similar to the "natural incidence" of HCC among previously reported hospitalized patients with HBV- and HCV-related liver cirrhosis.[5, 7, 36]

\section{Conclusions}

Patients with liver cirrhosis and hypersplenism who underwent prior splenectomy had a decreased incidence of $\mathrm{HCC}$ on long-term follow-up. Among patients with liver cirrhosis and portal hypertension who are not expected to undergo liver transplant in the moderate- or long-term future, splenectomy should be considered as a means to mitigate the risk of HCC development. Future research will need to validate these findings through more comprehensive studies that involved larger number of patients from different geographical locations including the West. 


\section{Abbreviations}

HCC, hepatocellular carcinoma; HBV, hepatitis B virus; HCV, hepatitis C virus; TIPS, transjugular intrahepatic portosystemic shunt; HBsAg, hepatitis B surface antigen; HBeAg, hepatitis B e antigen; HBcAb, anti-hepatitis B core antibodies; IFN-a,interferon-a; AFP, a-fetoprotein; SD, standard deviation; HR, hazard ratio; $\mathrm{Cl}$, confidence interval; $\mathrm{ALT}$, alanine aminotransferase; $\mathrm{AST}$, aspartate aminotransferase; TBIL, total bilirubin; TGF- $\beta$, transforming growth factor $-\beta$; IL-6, interleukin-6; HSP, heat shock protein; HO-1, heme oxygenase-1; PDGF, platelet growth factor; TACE, transcatheter arterial chemoembolization; TNF-a, tumor necrosis factor- $a$; HGF, hepatocyte growth factor; EGF, epidermal growth factor; NK cells, natural killer cells.

\section{Declarations}

Ethics approval and consent to participate and publication: The Ethics Committees of each participating centers (The Ethics Committee of School of Medicine of Xi'an Jiaotong University, Ningxia Medical University, Binzhou Medical University, School of Medicine of Nanchang University, Shaanxi University of Chinese Medicine) approved to participate in the current study and publish the data.

Consent for publication: Not applicable

Availability of data and material: The dataset used and/or analyzed during the current study are available from the corresponding author on reasonable request.

\section{Competing interests: none}

Funding: This work was supported by the Clinical Research Award of the First Affiliated Hospital of Xi'an Jiaotong University of China (No. XJTU1AF-CRF-2017-004). The funder has no role in study design, data collection, analyzation and interpretation, preparation of the manuscript or publication of the study.

Authors' contributions: (I) Conception and design: XFZ, YL, TMP; (II) Administrative support: YL; (III) Provision of study materials or patients: XFZ, YL, JHL, PL, XYZ, ZW, TL, XNW, HFD, ZDL, ZFL, RW, XC, JXW, PY, YL, JZ; (IV) Collection and assembly of data: XFZ, YL, JHL, PL, XYZ, ZW, TL, XNW, HFD, ZDL, $Z F L, R W, X C, J X W, P Y, Y L, J Z ;(V)$ Data analysis and interpretation: $X F Z, Y L, J H L, P L, X Y Z, Z W, T L, X N W$, HFD, ZDL; (VI) Manuscript writing: All authors; (VII) Final approval of manuscript: All authors

Acknowledgements: The authors would like to thank all the physicians in data collection and statistical analysis who are not listed in the authors from the seven University Hospitals.

\section{References}

1. Torre LA, Bray F, Siegel RL, Ferlay J, Lortet-Tieulent J, Jemal A: Global cancer statistics, 2012. $C A$ Cancer J Clin 2015, 65(2):87-108. 
2. Torre LA, Siegel RL, Ward EM, Jemal A: Global Cancer Incidence and Mortality Rates and Trends-An Update. Cancer Epidemiol Biomarkers Prev 2016, 25(1):16-27.

3. Chen JG, Zhang SW: Liver cancer epidemic in China: past, present and future. Semin Cancer Biol 2011, 21(1):59-69.

4. Schafer DF, Sorrell MF: Hepatocellular carcinoma. Lancet 1999, 353(9160):1253-1257.

5. Banares R, Nunez O, Escudero M, Fernandez C, Vaquero J, Beceiro I, Echenagusia A, Clemente G, Santos L: Patients with cirrhosis and bare-stent TIPS may have increased risk of hepatocellular carcinoma. Hepatology 2005, 41(3):566-571.

6. Bjorneboe M, Andersen JR, Christensen U, Skinhoj P, Jensen OM: Does a portal-systemic shunt increase the risk of primary hepatic carcinoma in cirrhosis of the liver? Scand $J$ Gastroenterol 1985, 20(1):59-64.

7. De Santis A, legri C, Kondili L, Riggio O, Salvatori FM, Catalano C, Di Martino M, Bassanelli C, Lupo M, Lucatelli $\mathrm{P}$ et al: Hepatocellular carcinoma in cirrhotic patients with transjugular intrahepatic portosystemic shunt: a retrospective case-control study. Dig Liver Dis 2014, 46(8):726-730.

8. Borentain P, Garcia S, Gregoire E, Vidal V, Ananian P, Ressiot E, Hardwigsen J, Bartoli JM, Moulin G, Botta-Fridlund $D$ et al: Transjugular intrahepatic porto-systemic shunt is a risk factor for liver dysplasia but not hepatocellular carcinoma: a retrospective study of explanted livers. Dig Liver Dis 2015, 47(1):57-61.

9. Elizalde JI, Castells A, Planas R, Rodriguez-Iglesias MP, Bruix J, Bru C, Salo J, Boix J, Gassull MA, Teres $\mathrm{J}$ et al: [Prevalence of hepatocellular carcinoma in cirrhotic patients with with portosystemic shunt. Cohort analysis]. Gastroenterol Hepatol 1996, 19(4):189-193.

10. Li A, Li Z, Ma S, Su Q, Zhang S, Sun X, Li G: Dysfunction of splenic macrophages in cirrthotic patients with hypersplenism and HBV infection. Am J Med Sci 2008, 336(1):32-38.

11. Asanoma M, Ikemoto T, Mori H, Utsunomiya T, Imura S, Morine Y, Iwahashi S, Saito Y, Yamada S, Shimada M: Cytokine expression in spleen affects progression of liver cirrhosis through liver-spleen cross-talk. Hepatol Res 2014, 44(12):1217-1223.

12. Takayashiki T, Yoshidome H, Kimura F, Ohtsuka M, Shimizu Y, Kato A, Ito H, Shimizu H, Ambiru S, Togawa A et al: Increased expression of toll-like receptor 4 enhances endotoxin-induced hepatic failure in partially hepatectomized mice. $J$ Hepatol 2004, 41(4):621-628.

13. Takeishi K, Kawanaka H, Itoh S, Harimoto N, Ikegami T, Yoshizumi T, Shirabe K, Maehara Y: Impact of Splenic Volume and Splenectomy on Prognosis of Hepatocellular Carcinoma Within Milan Criteria After Curative Hepatectomy. World J Surg 2018, 42(4):1120-1128.

14. Velazquez RF, Rodriguez M, Navascues CA, Linares A, Perez R, Sotorrios NG, Martinez I, Rodrigo L: Prospective analysis of risk factors for hepatocellular carcinoma in patients with liver cirrhosis. Hepatology 2003, 37(3):520-527.

15. Faitot F, Allard MA, Pittau G, Ciacio O, Adam R, Castaing D, Cunha AS, Pelletier G, Cherqui D, Samuel D et al: Impact of clinically evident portal hypertension on the course of hepatocellular carcinoma in patients listed for liver transplantation. Hepatology 2015, 62(1):179-187. 
16. Lv X, Yang F, Guo X, Yang T, Zhou T, Dong X, Long Y, Xiao D, Chen Y: Hypersplenism is correlated with increased risk of hepatocellular carcinoma in patients with post-hepatitis cirrhosis. Tumour Biol 2016, 37(7):8889-8900.

17. Lu SN, Wang JH, Liu SL, Hung CH, Chen CH, Tung HD, Chen TM, Huang WS, Lee CM, Chen CC et al: Thrombocytopenia as a surrogate for cirrhosis and a marker for the identification of patients at highrisk for hepatocellular carcinoma. Cancer 2006, 107(9):2212-2222.

18. Malinchoc M, Kamath PS, Gordon FD, Peine CJ, Rank J, ter Borg PC: A model to predict poor survival in patients undergoing transjugular intrahepatic portosystemic shunts. Hepatology 2000, 31(4):864871.

19. Hung HH, Chiou YY, Hsia CY, Su CW, Chou YH, Chiang JH, Kao WY, Huo TI, Huang YH, Su YH et al: Survival rates are comparable after radiofrequency ablation or surgery in patients with small hepatocellular carcinomas. Clin Gastroenterol Hepatol 2011, 9(1):79-86.

20. Mebius RE, Kraal G: Structure and function of the spleen. Nat Rev Immunol 2005, 5(8):606-616.

21. Fang J, Yang Y, Xiao W, Zheng B, Lv YB, Liu XL, Ding J: Extremely low frequency alternating magnetic field-triggered and MRI-traced drug delivery by optimized magnetic zeolitic imidazolate framework-90 nanoparticles. Nanoscale 2016, 8(6):3259-3263.

22. Yamada S, Morine Y, Imura S, Ikemoto T, Arakawa Y, Iwahashi S, Saito Y, Yoshikawa M, Teraoku H, Shimada M: Liver regeneration after splenectomy in patients with liver cirrhosis. Hepatol Res 2015:doi: 10.1111/hepr.12573.

23. Yada A, limuro Y, Uyama N, Uda Y, Okada T, Fujimoto J: Splenectomy attenuates murine liver fibrosis with hypersplenism stimulating hepatic accumulation of Ly-6C(lo) macrophages. J Hepatol 2015, 63(4):905-916.

24. Cao ZX, Chen XP, Wu ZD: Changes of immune function in patients with liver cirrhosis after splenectomy combined with resection of hepatocellular carcinoma. Hepatobiliary Pancreat Dis Int 2003, 2(4):562-565.

25. Inagaki Y, Sugimoto K, Shiraki K, Tameda M, Kusagawa S, Nojiri K, Ogura S, Yamamoto N, Takei Y, Ito $\mathrm{M}$ et al: The long-term effects of splenectomy and subsequent interferon therapy in patients with HCV-related liver cirrhosis. Mol Med Rep 2014, 9(2):487-492.

26. Li B, Zhang S, Huang N, Chen H, Wang P, Li J, Pu Y, Yang J, Li Z: Dynamics of the spleen and its significance in a murine $\mathrm{H} 22$ orthotopic hepatoma model. Exp Biol Med (Maywood) 2016, 241(8):863-872.

27. Long X, Wang J, Zhao JP, Liang HF, Zhu P, Cheng Q, Chen Q, Wu YH, Zhang ZG, Zhang BX et al: Splenectomy suppresses growth and metastasis of hepatocellular carcinoma through decreasing myeloid-derived suppressor cells in vivo. J Huazhong Univ Sci Technolog Med Sci 2016, 36(5):667676.

28. Yang HI, Yuen MF, Chan HL, Han KH, Chen PJ, Kim DY, Ahn SH, Chen CJ, Wong VW, Seto WK et al: Risk estimation for hepatocellular carcinoma in chronic hepatitis B (REACH-B): development and validation of a predictive score. Lancet Oncol 2011, 12(6):568-574. 
29. Wong VW, Chan SL, Mo F, Chan TC, Loong HH, Wong GL, Lui YY, Chan AT, Sung JJ, Yeo W et al: Clinical scoring system to predict hepatocellular carcinoma in chronic hepatitis B carriers. J Clin Oncol 2010, 28(10):1660-1665.

30. Yuen MF, Tanaka Y, Fong DY, Fung J, Wong DK, Yuen JC, But DY, Chan AO, Wong BC, Mizokami M et al: Independent risk factors and predictive score for the development of hepatocellular carcinoma in chronic hepatitis B. J Hepatol 2009, 50(1):80-88.

31. Yamada S, Morine Y, Imura S, Ikemoto T, Arakawa Y, Iwahashi S, Saito Y, Yoshikawa M, Teraoku H, Shimada M: Liver regeneration after splenectomy in patients with liver cirrhosis. Hepatol Res 2016, 46(5):443-449.

32. Lv X, Yang F, Guo X, Yang T, Zhou T, Dong X, Long Y, Xiao D, Chen Y: Erratum to: Hypersplenism is correlated with increased risk of hepatocellular carcinoma in patients with post-hepatitis cirrhosis. Tumour Biol 2016, 37(7):9989.

33. Huang N, Ji F, Zhang S, Pu Y, Jiang A, Zhou R, Ji Y, Wei W, Yang J, Li Z: Effect of Splenectomy on Serum Cytokine Profiles in Hepatitis B Virus-Related Cirrhosis Patients with Portal Hypertension. Viral Immunol 2018, 31(5):371-378.

34. Lesurtel M, Graf R, Aleil B, Walther DJ, Tian Y, Jochum W, Gachet C, Bader M, Clavien PA: Plateletderived serotonin mediates liver regeneration. Science 2006, 312(5770):104-107.

35. Liu G, Xie C, Fang Y, Qian K, Liu Q, Liu G, Cao Z, Du H, Fu J, Xu X: Splenectomy after partial hepatectomy accelerates liver regeneration in mice by promoting tight junction formation via polarity protein Par 3-aPKC. Life Sci 2018, 192:91-98.

36. Atiq O, Tiro J, Yopp AC, Muffler A, Marrero JA, Parikh ND, Murphy C, McCallister K, Singal AG: An Assessment of Benefits and Harms of Hepatocellular Carcinoma Surveillance in Patients with Cirrhosis. Hepatology 2016.

\section{Tables}

Table 1 Demographic, laboratorial and clinical data of patients in the two groups 


\begin{tabular}{|c|c|c|c|}
\hline & Splenectomy $(n=407)$ & Non-splenectomy $(n=464)$ & $p$ value \\
\hline Age (years) & $45 \pm 10$ & $47 \pm 4$ & 0.048 \\
\hline Male gender & $263(64.6 \%)$ & $340(73.3 \%)$ & 0.006 \\
\hline Child-Pugh score & $6 \pm 1$ & $7 \pm 1$ & $<0.001$ \\
\hline Child-Pugh Class & & & 0.004 \\
\hline A & $257(63.1 \%)$ & $248(53.4 \%)$ & \\
\hline B & $150(36.9 \%)$ & $216(46.6 \%)$ & \\
\hline MELD score & $0.6 \pm 0.6$ & $0.7 \pm 0.6$ & 0.032 \\
\hline Hepatitis & & & 0.142 \\
\hline $\mathrm{HBV} / \mathrm{HCV} / \mathrm{HBV}+\mathrm{HCV}$ & $362 / 41 / 4$ & $430 / 32 / 2$ & \\
\hline HBV DNA >1000 copy/ml* & $161(39.6 \%)$ & $226(48.7 \%)$ & 0.019 \\
\hline Anti-HBV treatments* & $199(48.9 \%)$ & $349(75.2 \%)$ & $<0.001$ \\
\hline HBeAg positive & $85(20.9 \%)$ & $122(26.3 \%)$ & 0.067 \\
\hline HCV RNA >100 copy/ml** & $26(6.4 \%)$ & $22(4.8 \%)$ & 0.532 \\
\hline Anti-HCV treatments** & $15(3.7 \%)$ & $22(4.7 \%)$ & 0.006 \\
\hline Diabetes mellitus & $31(7.6 \%)$ & $30(6.4 \%)$ & 0.444 \\
\hline Cigarette smoking & $100(24.6 \%)$ & $135(29.1 \%)$ & 0.146 \\
\hline Alcohol abuse & $52(12.8 \%)$ & $80(17.2 \%)$ & 0.232 \\
\hline White blood cell count $\left(\times 10^{9}\right)$ & $2.5 \pm 1.5$ & $3.8 \pm 1.8$ & $<0.001$ \\
\hline Red blood cell count $\left(\times 10^{12}\right)$ & $3.4 \pm 0.7$ & $3.2 \pm 0.8$ & 0.001 \\
\hline Hemoglobin $(g / L)$ & $99.6 \pm 21.8$ & $117.8 \pm 26.2$ & $<0.001$ \\
\hline Platelet count $\left(\times 10^{9}\right)$ & $43.9 \pm 23.8$ & $74.2 \pm 45.8$ & $<0.001$ \\
\hline Alanine aminotransferase $(\mathrm{U} / \mathrm{L})$ & $36.5 \pm 24.4$ & $56.4 \pm 51.6$ & $<0.001$ \\
\hline Aspartate aminotransferase (U/L) & $43.5 \pm 24.6$ & $59.2 \pm 46.5$ & $<0.001$ \\
\hline Total bilirubin $(\mu \mathrm{mol} / \mathrm{L})$ & $23.7 \pm 12.8$ & $30.6 \pm 23.1$ & 0.005 \\
\hline $\operatorname{Albumin}(\mathrm{g} / \mathrm{L})$ & $36.0 \pm 5.2$ & $34.1 \pm 6.1$ & $<0.001$ \\
\hline Blood urea nitrogen (mmol/L) & $5.2 \pm 1.8$ & $5.1 \pm 2.6$ & 0.479 \\
\hline Blood creatinine $(\mu \mathrm{mol} / \mathrm{L})$ & $67.7 \pm 20.3$ & $70.3 \pm 20.5$ & 0.231 \\
\hline Prothrombin time (s) & $14.3 \pm 1.9$ & $14.8 \pm 2.5$ & 0.150 \\
\hline
\end{tabular}




\begin{tabular}{|llll|}
\hline International normalized ratio & $1.2 \pm 0.2$ & $1.2 \pm 0.2$ & 0.204 \\
\hline Follow-up, median (range) $\llbracket$ months & $63(8-103)$ & $62(12-104)$ & 0.532 \\
\hline
\end{tabular}

MELD, the Model for end-stage liver disease; HBV, hepatitis B virus; $\mathrm{HCV}$, hepatitis C virus; $\mathrm{HBeAg}$, hepatitis $B$ e antigen; * compared only in HBV positive patients; ** compared only in HCV positive patients.

Table 2. Demographic, laboratorial and clinical data of patients in the two groups after propensity score matching

\begin{tabular}{|llll|}
\hline & $\begin{array}{l}\text { Splenectomy } \\
(\mathrm{n}=233)\end{array}$ & Non-splenectomy $(\mathrm{n}=233)$ & $p$ value \\
\hline Age (years) & $47 \pm 10$ & $47 \pm 12$ & 0.584 \\
\hline Male gender & $157(67.4 \%)$ & $166(71.2 \%)$ & 0.422 \\
\hline Child-Pugh score & $6 \pm 1$ & $6 \pm 1$ & 0.440 \\
\hline Child-Pugh Class & & & 0.775 \\
\hline A & $142(60.9 \%)$ & $146(62.7 \%)$ & \\
\hline B & $91(39.1 \%)$ & $87(37.3 \%)$ & 0.874 \\
\hline MELD score & $0.6 \pm 0.6$ & $0.6 \pm 0.6$ & 0.235 \\
\hline Hepatitis & & & 0.292 \\
\hline HBV/HCV/HBV+HCV & $213 / 18 / 2$ & $209 / 24 / 0$ & 0.956 \\
\hline HBV DNA >1000 copy/ml* & $96(41.2 \%)$ & $104(44.6 \%)$ & 0.742 \\
\hline HCV RNA >100 copy/ml** & $11(4.7 \%)$ & $13(5.6 \%)$ & 0.934 \\
\hline HBeAg positive & $52(22.3 \%)$ & $56(24.0 \%)$ & 0.204 \\
\hline Anti-HBV treatments* & $168(72.1 \%)$ & $164(70.4 \%)$ & 1.000 \\
\hline Anti-HCV treatments** & $13(5.6 \%)$ & $11(4.7 \%)$ & 0.456 \\
\hline Diabetes mellitus & $18(7.7 \%)$ & $19(8.2 \%)$ & 0.232 \\
\hline Cigarette smoking & $55(23.6 \%)$ & $63(27.0 \%)$ & $38(16.3 \%)$ \\
\hline Alcohol abuse & $28(12.0 \%)$ & & \\
\hline & & & \\
\hline
\end{tabular}

HBV, hepatitis B virus; HBeAg, hepatitis B e antigen; * compared only in HBV positive patients; ** compared only in HCV positive patients. 
Table 3. Cox proportional hazard regression model of variables associated with development of hepatocellular carcinoma 


\begin{tabular}{|c|c|c|c|c|c|c|c|}
\hline \multirow[b]{2}{*}{ Variables } & \multirow[b]{2}{*}{$\begin{array}{l}\text { Classification } \\
\text { criteria }\end{array}$} & \multirow[b]{2}{*}{$\mathrm{n}$} & \multirow[b]{2}{*}{ events } & \multicolumn{2}{|c|}{ Univariate analysis } & \multicolumn{2}{|c|}{ Multivariate analysis } \\
\hline & & & & $\mathrm{HR}(95 \% \mathrm{Cl})$ & $\begin{array}{l}P \\
\text { value }\end{array}$ & $\mathrm{HR}(95 \% \mathrm{Cl})$ & $\begin{array}{l}\mathrm{P} \\
\text { value }\end{array}$ \\
\hline \multirow[t]{2}{*}{ Age (years) } & $\leq 40$ & 269 & 23 & 1 & & & \\
\hline & $>40$ & 602 & 101 & $\begin{array}{l}2.16(1.37- \\
3.39)\end{array}$ & 0.001 & $\begin{array}{l}2.18(1.38- \\
3.46)\end{array}$ & 0.001 \\
\hline \multirow[t]{2}{*}{ Gender } & Female & 268 & 25 & 1 & & & \\
\hline & Male & 603 & 99 & $\begin{array}{l}1.92(1.24- \\
2.98)\end{array}$ & 0.004 & $\begin{array}{l}1.72(1.06- \\
2.78)\end{array}$ & 0.027 \\
\hline \multirow[t]{2}{*}{ CP Class } & $A$ & 534 & 73 & 1 & & & \\
\hline & B & 337 & 51 & $\begin{array}{l}1.14(0.80- \\
1.64)\end{array}$ & 0.460 & & \\
\hline \multirow[t]{2}{*}{ HBV } & $\leq 1000 \mathrm{copy} / \mathrm{ml}$ & 411 & 49 & 1 & & & \\
\hline & $>1000$ copy/ml & 387 & 66 & $\begin{array}{l}1.44(0.99- \\
2.08)\end{array}$ & 0.055 & $\begin{array}{l}1.36(0.95- \\
1.94)\end{array}$ & 0.096 \\
\hline \multirow[t]{2}{*}{ Anti-HBV } & No & 250 & 29 & 1 & & & \\
\hline & Yes & 548 & 86 & $\begin{array}{l}0.66(0.43- \\
1.009)\end{array}$ & 0.055 & $\begin{array}{l}0.75(0.50- \\
1.12)\end{array}$ & 0.161 \\
\hline \multirow[t]{2}{*}{$\mathrm{HCV}$} & $\leq 1000 \mathrm{copy} / \mathrm{ml}$ & 31 & 4 & 1 & & & \\
\hline & $>1000$ copy/ml & 48 & 6 & $\begin{array}{l}0.87(0.24- \\
3.11)\end{array}$ & 0.866 & & \\
\hline \multirow[t]{2}{*}{ Anti-HCV } & No & 42 & 5 & 1 & & & \\
\hline & Yes & 37 & 5 & $\begin{array}{l}0.81(0.23- \\
2.84)\end{array}$ & 0.813 & & \\
\hline \multirow[t]{2}{*}{ Smoking } & No & 636 & 76 & 1 & & & \\
\hline & Yes & 235 & 48 & $\begin{array}{l}1.91(1.33- \\
2.75)\end{array}$ & $<0.001$ & $\begin{array}{l}1.45(0.98- \\
2.15)\end{array}$ & 0.067 \\
\hline \multirow{2}{*}{$\begin{array}{l}\text { Alcohol } \\
\text { use }\end{array}$} & No & 739 & 100 & 1 & & & \\
\hline & Yes & 132 & 24 & $\begin{array}{l}1.39(0.89- \\
2.18)\end{array}$ & 0.146 & & \\
\hline \multirow[t]{2}{*}{ Diabetes } & No & 800 & 113 & 1 & & & \\
\hline & Yes & 61 & 8 & $\begin{array}{l}0.87(0.42- \\
1.78)\end{array}$ & 0.702 & & \\
\hline Treatments & Non-splenectomy & 464 & 75 & 1 & & & \\
\hline
\end{tabular}


$\mathrm{CP}$, Child-Pugh; $\mathrm{HBV}$, hepatitis B virus; $\mathrm{HCV}$, hepatitis $\mathrm{C}$ virus; $\mathrm{HR}$, hazard ratio; $\mathrm{Cl}$, confidence interval

Table 4. Clinical characteristics and treatments of patients developing hepatocellular carcinoma in the two comparison cohorts of patients

\begin{tabular}{|llll|}
\hline & Splenectomy & Non-splenectomy & P value \\
\hline Hepatocellular carcinoma & $49(12.0 \%)$ & $75(16.2 \%)$ & 0.005 \\
\hline Age & $49 \pm 11$ & $51 \pm 10$ & 0.345 \\
\hline Male gender & $38(77.6 \%)$ & $61(81.3 \%)$ & 0.651 \\
\hline Hepatitis & & & 0.739 \\
\hline B & $45(91.8 \%)$ & $70(93.3 \%)$ & \\
\hline C & $4(8.2 \%)$ & $5(6.7 \%)$ & \\
\hline Tumor size (cm) & $5.8 \pm 2.8$ & $5.0 \pm 2.4$ & 0.091 \\
\hline Tumor location & & & 0.744 \\
\hline Right lobe & $31(70 \%)$ & $49(45.8 \%)$ & \\
\hline Left lobe & $7(10 \%)$ & $13(20.8 \%)$ & \\
\hline Bilobar & $11(20 \%)$ & $13(33.4 \%)$ & \\
\hline Tumor number & & & \\
\hline single & $25(51.0 \%)$ & $27(36.0 \%)$ & \\
\hline multiple & $24(49.0 \%)$ & $48(64.0 \%)$ & \\
\hline Treatments & $21(42.9 \%)$ & $23(30.7 \%)$ & \\
\hline Surgical resection & $6(12.2 \%)$ & $25(33.3 \%)$ & \\
\hline Liver transplant & $2(4.1 \%)$ & $4(5.3 \%)$ & \\
\hline TACE/RFA & & $27(36.0 \%)$ & \\
\hline Supportive treatments & $22.9 \%)$ & \\
\hline
\end{tabular}

TACE, transcatheter arterial chemoembolization; RFA, radiofrequency ablation.

\section{Figures}



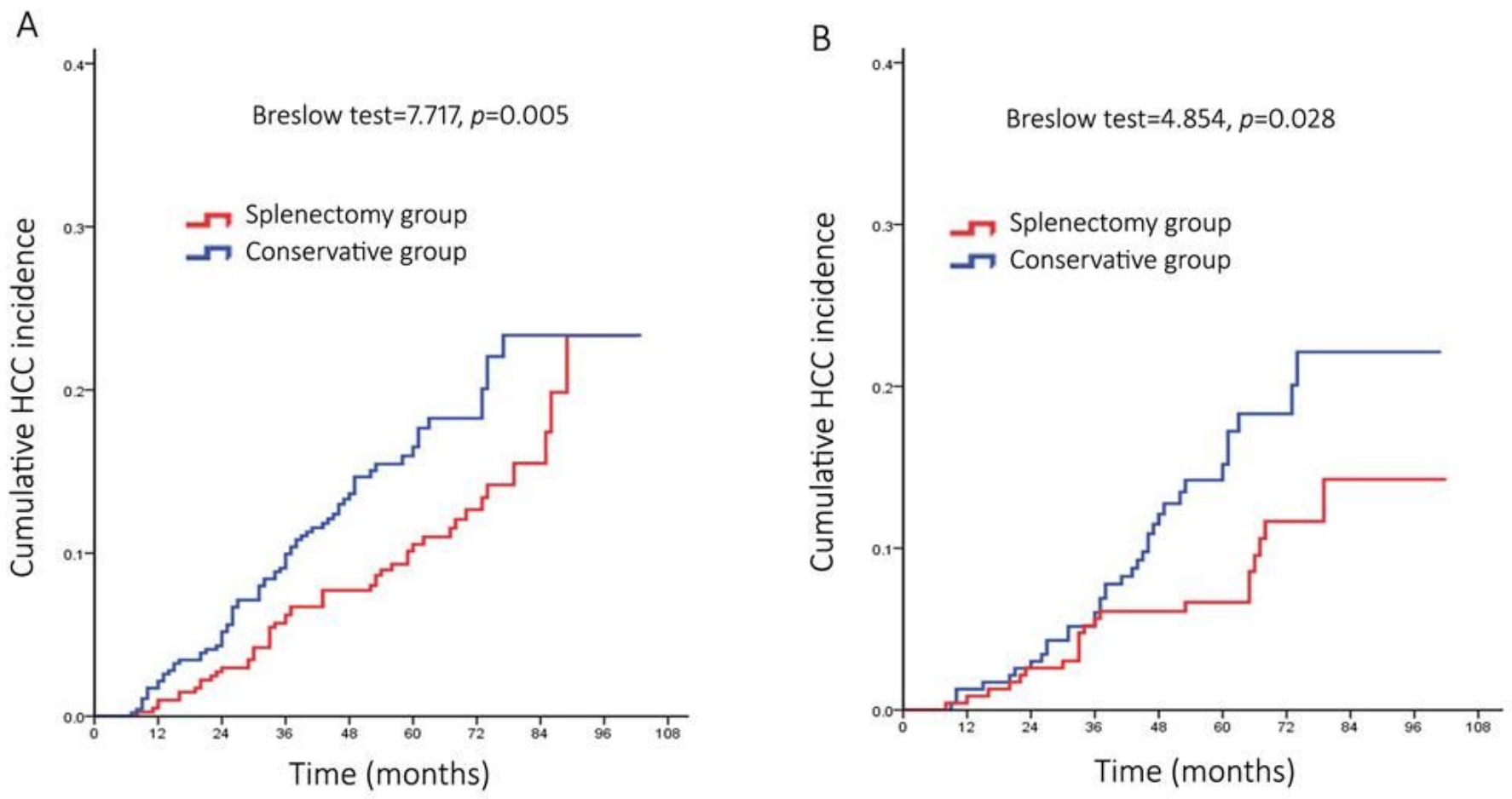

\section{Figure 1}

Cumulative incidence of hepatocellular carcinoma in splenectomy and non-splenectomy groups before (A) and after (B) propensity score matching analysis ( $p=0.005$ and 0.028 , respectively).

A

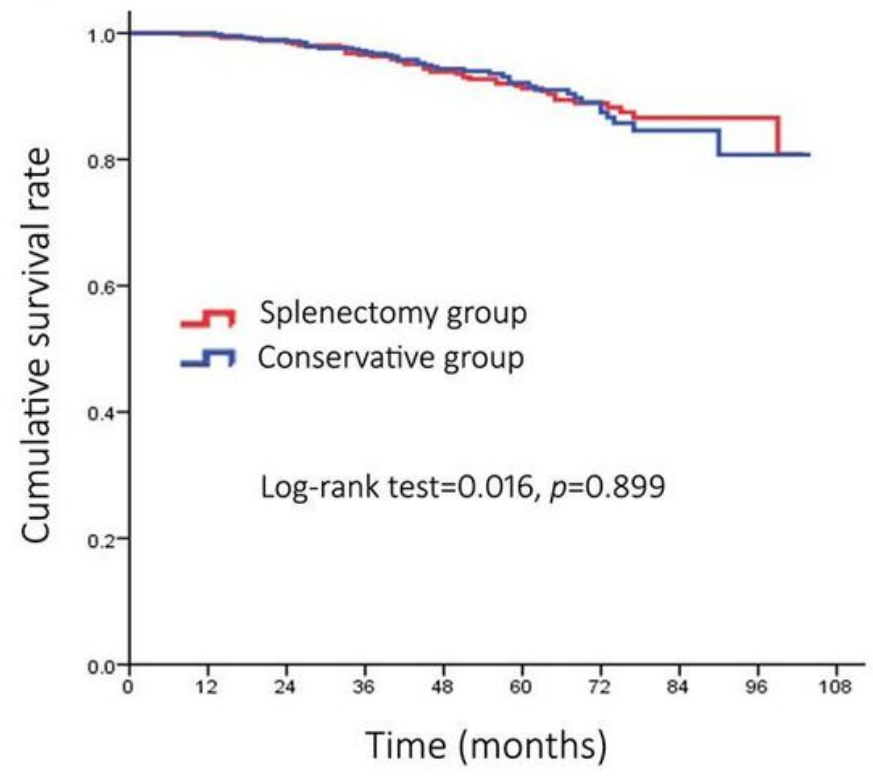

B

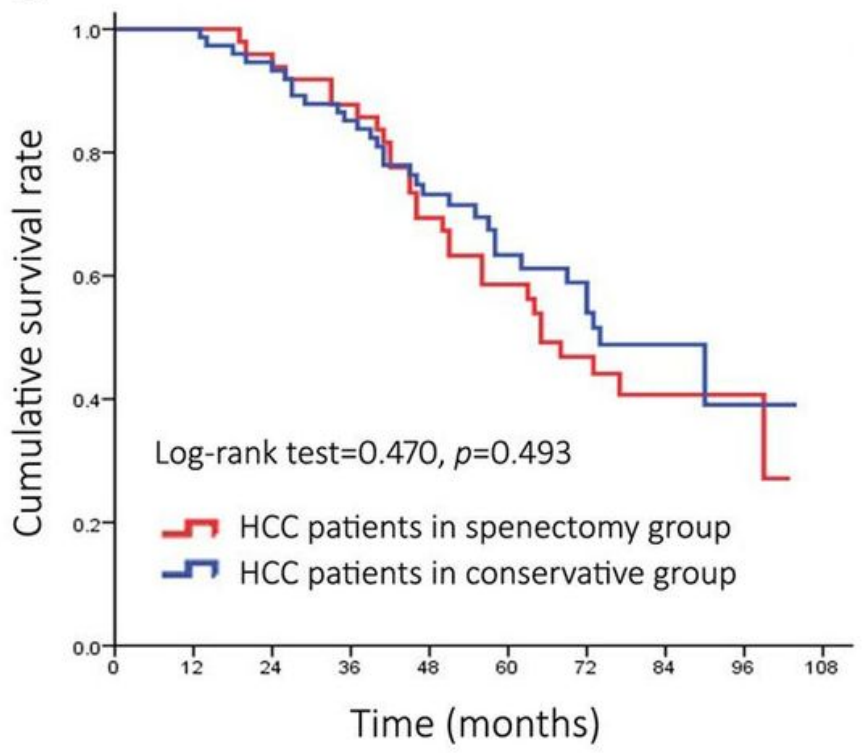


Figure 2

A. Overall survival of the patients in splenectomy and non-splenectomy groups $(p=0.899)$. B. Overall survival of the patients with hepatocellular carcinoma in splenectomy and non-splenectomy groups $(p=0.493)$.

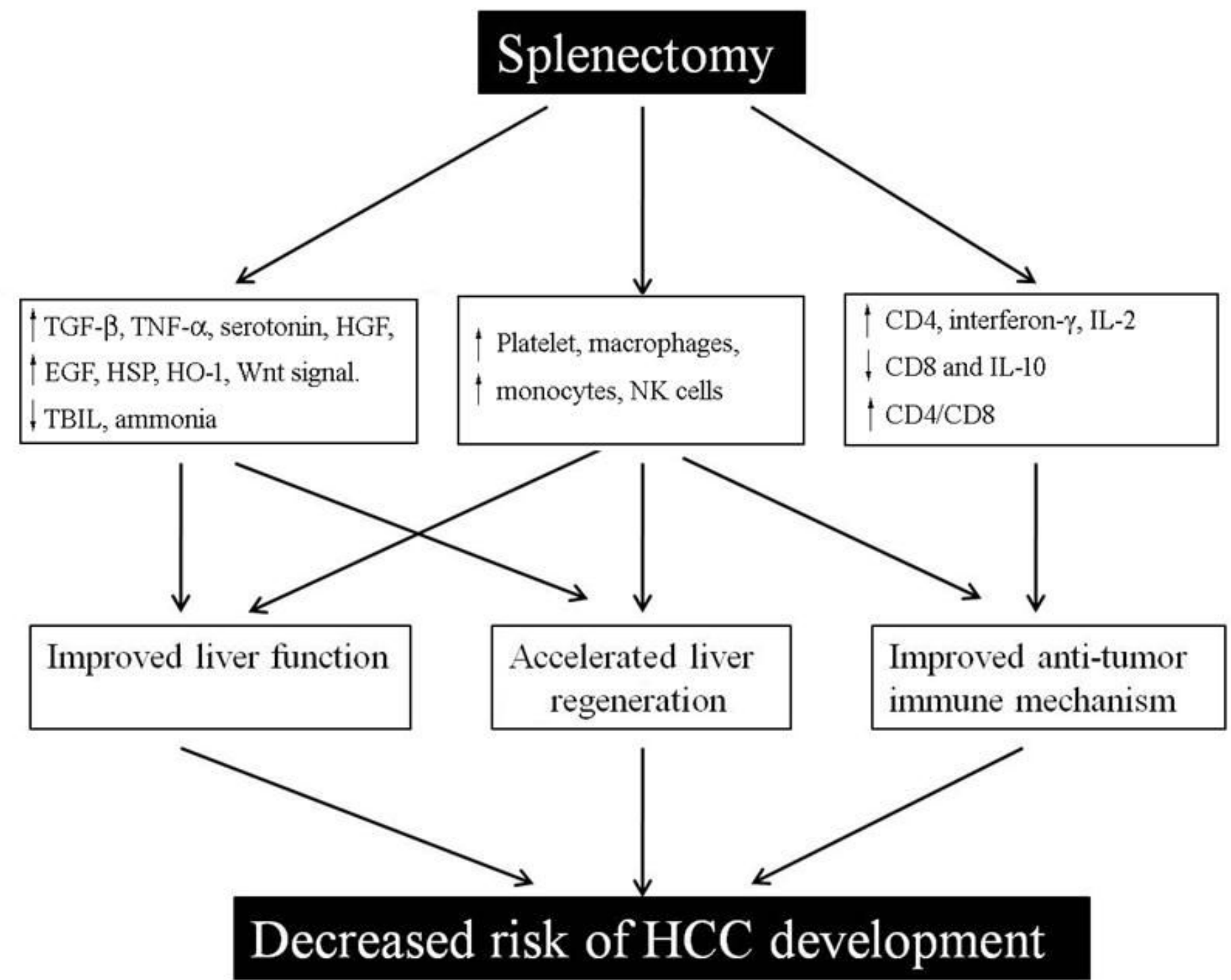

Figure 3

Possible mechanism concerning impacts of splenectomy on development of hepatocellular carcinoma in patients with liver cirrhosis and portal hypertension. 